\title{
ChemComm
}

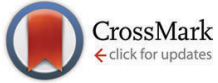

Cite this: Chem. Commun., 2016, 52,6072

Received 18th January 2016, Accepted 23rd February 2016

DOI: $10.1039 / c 5 c c 09719 c$

www.rsc.org/chemcomm

\section{Nanocrystalline SSZ-39 zeolite as an efficient catalyst for the methanol-to-olefin (MTO) process $\dagger$}

\author{
Nuria Martín, ${ }^{a}$ Zhibin Li, ${ }^{\text {ab }}$ Joaquín Martínez-Triguero, ${ }^{a}$ Jihong $\mathrm{Yu}^{\mathrm{c}}$ \\ Manuel Moliner*a and Avelino Corma*a
}

The synthesis of nanosized SSZ-39 zeolite has been achieved using a high silica FAU zeolite as the Si and Al source and tetraethylphosphonium (TEP) cations as OSDAs. The obtained SSZ-39 material shows a remarkably high catalyst lifetime compared to conventional SSZ-13 and SSZ-39 materials.

Light olefins, such as ethylene and propylene, are mainly obtained from fluid catalytic cracking ${ }^{1}$ and from steam cracking of hydrocarbons, preferentially LPG and naphtha. ${ }^{2}$ However, in the last few years, since methanol could be efficiently obtained from different non-petroleum based feedstocks, such as coal or natural gas, the production of these light olefins from methanol through the so-called methanol-to-olefin (MTO) process has been notoriously increased. ${ }^{3}$

One of the commercial catalysts for the MTO reaction is the SAPO-34, which is the silicoaluminophosphate form of the CHA material. ${ }^{4}$ The excellent catalytic behaviour of the SAPO-34 for the MTO process could be mainly explained by the presence of large cavities and small pores combined with mild acidity. ${ }^{3 c, 5}$ Indeed, the large cavities allow the formation of the required large "hydrocarbon pool" intermediates to produce the light olefins, ${ }^{6}$ and the small pores favor the diffusion of the desired linear light olefins versus aromatic or branched molecules.

However, the formation of these large organic species within the large cavities ("hydrocarbon pool"), combined with severe mass transfer restrictions, results in a fast deactivation of the MTO catalyst by coke formation and low catalyst utilization. ${ }^{7}$ Thus, the mass transfer rate enhancement will be a key objective

\footnotetext{
${ }^{a}$ Instituto de Tecnología Quimica (UPV-CSIC), Universidad Politécnica de Valencia, Consejo Superior de Investigaciones Cientificas, Valencia, 46022, Spain. E-mail: acorma@itq.upv.es,mmoliner@itq.upv.es

${ }^{b}$ School of Chemistry and Materials Science, Heilongjiang University, Harbin 150080, China

${ }^{c}$ State Key Laboratory of Inorganic Synthesis and Preparative Chemistry, College of Chemistry, Jilin University, 2699 Qianjin Street, Changchun 130012, China

$\dagger$ Electronic supplementary information (ESI) available: Synthesis and catalytic experimental details, chemical analyses, ${ }^{31} \mathrm{P}$ and ${ }^{27} \mathrm{Al}$ MAS NMR and $\mathrm{NH}_{3}$-TPD profiles. See DOI: $10.1039 / \mathrm{c} 5 \mathrm{cc} 09719 \mathrm{c}$
}

to increase the catalytic activity and catalyst lifetime for the MTO reaction in the design of new small pore zeolite catalysts. ${ }^{8}$ In this sense, the generation of intra-crystalline mesoporosity, ${ }^{9}$ or the reduction of the crystal size to the nanometer scale, ${ }^{10}$ has allowed the increase of the catalytic properties of the SAPO- 34 .

Besides SAPO-34, the silicoaluminate form of CHA, SSZ-13, has also been described as a very efficient catalyst for the MTO reaction. ${ }^{11}$ This was especially so when some mesoporosity was generated in the zeolite crystals, or the zeolite was synthesized in the form of very small crystal sizes. ${ }^{12}$ It is worth noting that, in general, the hydrothermal stability and Brönsted acidity of silicoaluminate materials are higher than those of their silicoaluminophosphate counterparts, especially at low and moderate temperatures. ${ }^{13}$ Therefore, the design of silicoaluminate materials with the adequate physico-chemical properties for the MTO reaction is a matter of interest for the preparation of new commercial catalysts for the MTO process.

When considering other potential zeolites as catalysts for MTO, SSZ-39 is a silicoaluminate material with the AEI structure that, as chabazite, shows the presence of large cavities interconnected through small pore openings. ${ }^{14}$ Despite the structural similarities between CHA and AEI frameworks, there are very few reports using the SSZ-39 zeolite as a catalyst for the MTO reaction. ${ }^{15}$ Perhaps the limited synthesis conditions to obtain crystalline SSZ-39 materials could explain the small number of reports on this zeolite as MTO catalysts. ${ }^{14 a, 16}$ Indeed, with the former synthesis procedure, the SSZ-39 material can only be synthesized under very restricted $\mathrm{Si} / \mathrm{Al}$ ratios $(\sim 8)$, very low solid yields (below 50\%), and relatively large crystal sizes $(0.5-1 \mu \mathrm{m}){ }^{14 a, 16}$

Nevertheless, the synthesis of the SSZ-39 has been remarkably improved in the last few years following zeolite-to-zeolite transformations, using high-silica FAU zeolites as silicon and aluminum precursors, and tetraethylphosphonium (TEP) ${ }^{17}$ or $N, N$-dimethyl3,5-dimethylpiperidinium (DMP) ${ }^{18}$ as organic structure directing agents (OSDAs). These novel synthesis methodologies allow the improvement of the solid yields up to $90 \%$, and the $\mathrm{Si} / \mathrm{Al}$ ratios of the synthesized materials up to $16,{ }^{17 b, 18}$ but the reported crystal sizes are similar to the ones described for the original SSZ-39 
material $(0.5-1 \mu \mathrm{m}) .{ }^{17}$ However, the preparation of the SSZ-39 material in the nanosized form would be of much interest for the application of this zeolite for the MTO process.

Decreasing the crystal size of the SSZ-39 material, requires the acceleration of the nucleation step during its hydrothermal synthesis. Taking this into account, we have made the hypothesis that the use of the FAU zeolite as a zeolitic precursor under the adequate synthesis conditions could increase the rate of formation of the SSZ-39-precursor nuclei, since both zeolitic materials present common small structural building units within their structures, as the double-six member rings (D6Rs). Therefore, if faster nucleation rates are achieved during the synthesis of the SSZ-39 material, samples with smaller crystallite size could be obtained.

Herein, we present the preparation of the SSZ-39 zeolite with nanosized crystals of 40-50 $\mathrm{nm}$, which has been synthesized following a zeolite-to-zeolite transformation procedure, using a high-silica FAU as the silicon and aluminum source and TEP as OSDA. This nanosized SSZ-39 material shows excellent catalytic properties for the MTO reaction, including a remarkably long lifetime compared to standard SSZ-13 and SSZ-39 materials. The nanosized SSZ-39 crystals allow the improvement of the diffusion rate of the reactants and products involved in the MTO reaction, and notoriously decrease the negative effect of coke deposition within the zeolitic cavities.

To synthesize the SSZ-39 material with small crystal sizes, a high-silica FAU zeolite has been used as the silicon/aluminum source and two different organic molecules, DMP and TEP, as OSDAs, respectively. Then, the influence of the presence and concentration of alkali cations in the synthesis media and the dilution of the gel have been studied since they are two well-known variables that can influence the size of the zeolitic crystals during the hydrothermal synthesis. ${ }^{19}$ Thus, the following molar ratios of $\mathrm{NaOH} / \mathrm{Si}$ and $\mathrm{H}_{2} \mathrm{O} / \mathrm{Si}[0.05,0.1,0.2]$ and $[5,15]$, respectively, have been studied for each OSDA. The remaining synthesis conditions are $\mathrm{Si} / \mathrm{Al}=11$ and $\mathrm{OSDA} / \mathrm{Si}=0.2$, and the crystallization of the resultant gels was carried out at $135{ }^{\circ} \mathrm{C}$ (DMP) or $150{ }^{\circ} \mathrm{C}$ (TEP) for 9 days under static conditions.

The results for each OSDA are summarized in Fig. S1 (ESI $\dagger$ ). As can be seen there, different SSZ-39 materials can be obtained using the two proposed OSDAs, requiring slightly different synthesis conditions depending on the OSDA [see SSZ-39_1 and SSZ-39_2 in Fig. S1 (ESI $\dagger$ )]. Under the studied conditions, higher $\mathrm{NaOH} / \mathrm{Si}$ ratios are required to achieve pure crystalline SSZ-39 materials using the ammonium-based OSDA $[\mathrm{NaOH} / \mathrm{Si}$ $\sim 0.2$, see SSZ-39_1 in Fig. S1 (ESI $\dagger)]$ than when using the phosphonium-based OSDA $[\mathrm{NaOH} / \mathrm{Si} \sim 0.1$, see SSZ-39_2 in Fig. S1 (ESI $\dagger)]$. It is worth noting that the previously reported SSZ-39 synthesis using TEP as the OSDA described by Sano et al. also required a $\mathrm{NaOH} / \mathrm{Si}$ molar ratio of $0.1 .^{17}$

The PXRD patterns of the SSZ-39_1 and SSZ-39_2 samples reveal the crystallization of the pure AEI structure (see Fig. 1), but the different width and overlapping of the diffraction peaks suggest the presence of different crystal sizes for the two samples. Indeed, different crystal sizes were observed by scanning electron microscopy (SEM, see Fig. 2). The SSZ-39_1 sample shows homogeneous crystal sizes of 0.2-0.4 $\mu \mathrm{m}$ (see Fig. 2), while the SSZ-39_2

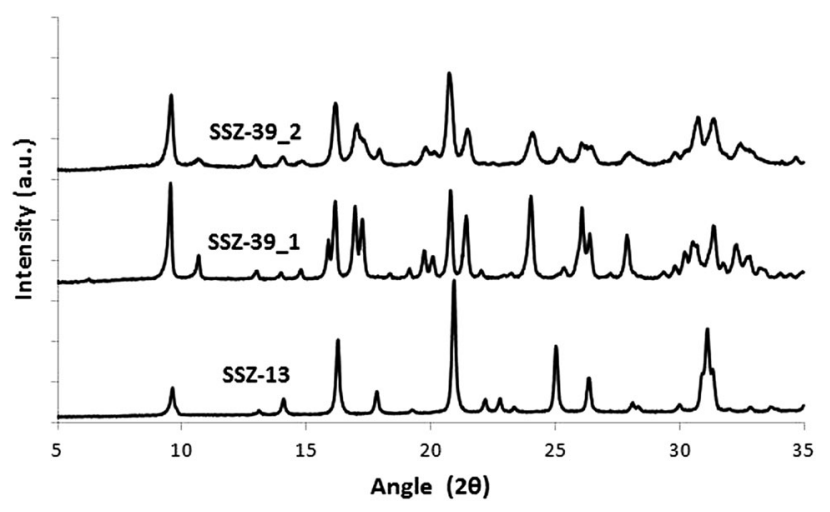

Fig. 1 PXRD patterns of the as-synthesized SSZ-39 and SSZ-13 materials.
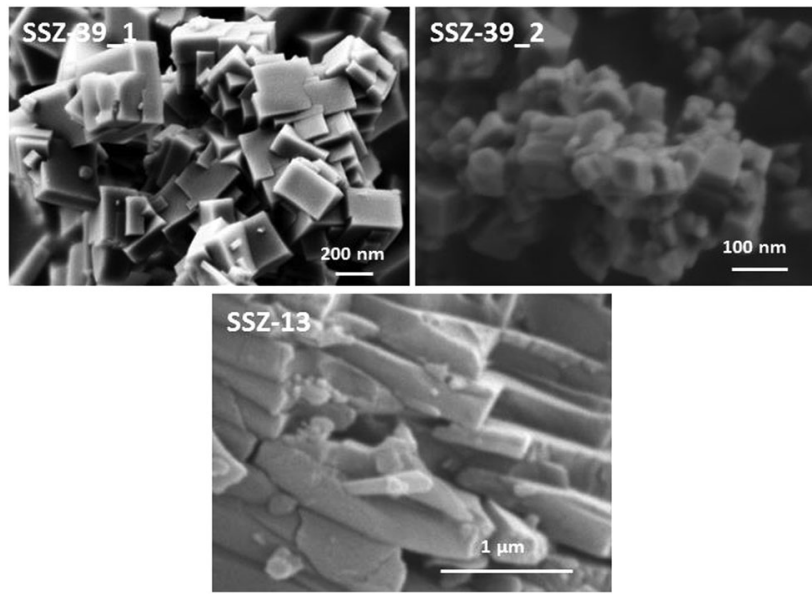

Fig. 2 SEM images of the SSZ-39 and SSZ-13 materials.

sample possesses much smaller crystal sizes within the nanoscale range ( 40-50 nm, see Fig. 2).

Although the preferential directing effect of the phosphoniumbased OSDA to form nanosized SSZ-39 crystals is not fully understood, the stronger interactions of the phosphonium species in the synthesis media with the inorganic species may result in an increase in the ratios of the nucleation/crystallization rates. ${ }^{19 b}$ Additional synthesis and characterization studies are currently being performed to test this hypothesis.

The as-prepared SSZ-39_1 and SSZ-39_2 materials have been calcined in air at $550{ }^{\circ} \mathrm{C}$ to remove the organic species occluded within the crystalline structures. It is important to note that the SSZ-39_2 material has been first treated under a hydrogen atmosphere at $800{ }^{\circ} \mathrm{C}$ for $4 \mathrm{~h}$ to favour the decomposition/elimination of most of the phosphorous-containing species. The ${ }^{31} \mathrm{P}$ MAS NMR spectrum of the as-prepared SSZ-39_2 material shows the presence of a single band centered at $\sim 40$ ppm [see SSZ-39_2_a.p. in Fig. S2 $(\mathrm{ESI} \dagger)]$, which is characteristic for phosphonium species, indicating that the entrapped TEP molecules are intact within the AEI structure. Moreover, chemical analysis reveals a $\mathrm{P} / \mathrm{TO}_{2}(\mathrm{~T}=\mathrm{Si}, \mathrm{Al})$ molar ratio of $\sim 0.085$, which corresponds to $\sim 1$ TEP molecule per cavity. After the thermal treatment with $\mathrm{H}_{2}$, almost $80-85 \%$ of the initial phosphorous is removed, and the small amount of residual phosphorous species remain as extra-framework phosphate 
species [see the ${ }^{31} \mathrm{P}$ MAS NMR spectrum for the SSZ-39_2_calc material in Fig. S2 (ESI $\dagger$ )]. Finally, the samples have been ammonium exchanged to remove the extra-framework sodium cations, followed by calcination in air at $500{ }^{\circ} \mathrm{C}$ to generate the acid form of the SSZ-39 zeolites.

These calcined materials have been characterized by $\mathrm{N}_{2}$ adsorption to study their textural properties. Both materials show similar BET surface area $\left[\sim 520 \mathrm{~m}^{2} \mathrm{~g}^{-1}\right.$, see Table S1 (ESI $\left.\left.\dagger\right)\right]$ but, as expected by its lower crystal size, the SSZ-39_2 material presents higher external surface area and lower micropore volume $\left(42 \mathrm{~m}^{2} \mathrm{~g}^{-1}\right.$ and $0.23 \mathrm{~cm}^{3} \mathrm{~g}^{-1}$, respectively) than the SSZ-39_1 material $\left[15 \mathrm{~m}^{2} \mathrm{~g}^{-1}\right.$ and $0.25 \mathrm{~cm}^{3} \mathrm{~g}^{-1}$, respectively, see Table S1 (ESI $\dagger$ )].

The chemical analyses of the ammonium-exchanged and calcined SSZ-39 materials indicate similar Si/Al ratios $(\sim 8.5$, see Table S1 (ESI +$)$ ) and the absence of sodium cations in both final solids. The coordination of aluminum atoms within the acid SSZ-39 materials has been studied by solid ${ }^{27} \mathrm{Al}$ MAS NMR spectroscopy. Both acid SSZ-39 materials show similar ${ }^{27} \mathrm{Al}$ MAS NMR spectra, presenting a main band centered at $\sim 55 \mathrm{ppm}$, a broad shoulder between 45 and $20 \mathrm{ppm}$, and finally, a small band centered at $\sim-10-0 \mathrm{ppm}$, which have been assigned to tetrahedrally coordinated $\mathrm{Al}$ in framework positions, distorted tetrahedrally coordinated Al species in framework positions, and octahedrally coordinated extra-framework aluminum species, ${ }^{20}$ respectively [see SSZ-39_1_Exc and SSZ-39_2_Exc in Fig. S3 (ESI $\dagger$ )].

The Brönsted acidity of these samples has been measured by means of the temperature-programmed desorption (TPD) of ammonia. The acid SSZ-39 materials show similar $\mathrm{NH}_{3}$ desorption curves, both presenting a maximum desorption band centered between 420 and $450{ }^{\circ} \mathrm{C}$ [see SSZ-39_1 and SSZ-39_2 in Fig. S4 $(\mathrm{ESI}+)]$. The quantification of the desorbed ammonia molecules reveals that both SSZ-39 materials show analogous Brönsted acidities ( $\sim 0.5 \mathrm{mmol} \mathrm{NH}_{3}$ per $\mathrm{g}$, see Table S2 (ESI $\left.\dagger\right)$ ).

For comparison purposes, a standard SSZ-13 zeolite has also been prepared under conventional synthesis conditions using the $N, N, N$-trimethyladamantammonium (TMAda) cation as an OSDA (see synthesis conditions in the experimental section). ${ }^{21}$ The PXRD pattern of this material confirms the crystallization of the pure CHA structure (see SSZ-13 in Fig. 1), and the SEM microscopy image indicates that the crystal sizes obtained for the conventional SSZ-13 material $(\sim 1 \times 0.2 \mu \mathrm{m}$, see Fig. 2$)$ are larger than those achieved for the SSZ-39 materials (see Fig. 2). The textural properties of the SSZ-13 material have been measured by $\mathrm{N}_{2}$ adsorption, giving a BET surface area and a micropore volume of $520 \mathrm{~m}^{2} \mathrm{~g}^{-1}$ and $0.25 \mathrm{~cm}^{3} \mathrm{~g}^{-1}$, respectively, which are analogous to the values achieved for the acid SSZ-39_1 material [see Table S1 (ESI + )]. Finally, the acidity of the SSZ-13 material has been measured using $\mathrm{NH}_{3}$-TPD. The amount of ammonia desorbed in the SSZ-13 material is lower $\left[\sim 0.35 \mathrm{mmol} \mathrm{NH}_{3}\right.$ per $\mathrm{g}$, see Table S2 (ESI $\left.\left.\dagger\right)\right]$ than the amount desorbed in the SSZ-39 materials $[\sim 0.50 \mathrm{mmol}$ $\mathrm{NH}_{3}$ per g, see Table S2 (ESI $\left.\left.\dagger\right)\right]$. The lowest acidity measured for the SSZ-13 material could be mainly attributed to its higher Si/Al ratio $(\sim 15)$ compared to SSZ-39 materials ( $\mathrm{Si} / \mathrm{Al} \sim 8.5)$, but the presence of larger diffusion paths within the larger crystal sizes of the SSZ-13 material may also influence the amount of desorbed ammonia.

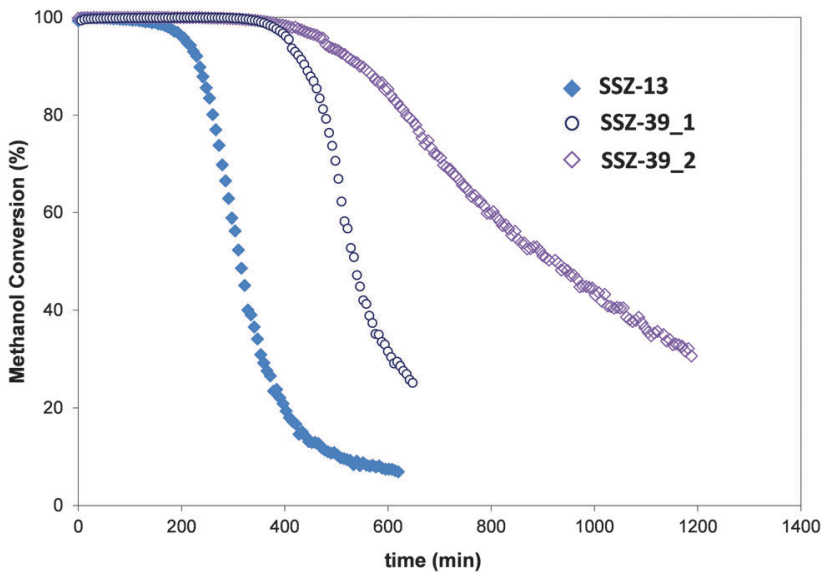

Fig. 3 Conversion of methanol on the SSZ-13 and SSZ-39 materials (reaction conditions: $T=350{ }^{\circ} \mathrm{C}, \mathrm{WHSV}=0.8 \mathrm{~h}^{-1}, W_{\text {cat }}=50 \mathrm{mg}$ ).

The catalytic activity of the SSZ-13 and SSZ-39 materials has been evaluated for the methanol to olefin (MTO) reaction at WHSV $=0.8 \mathrm{~h}^{-1}$ and $350{ }^{\circ} \mathrm{C}$ (see reaction conditions in the experimental section). The initial methanol conversion for the three samples is complete $(100 \%)$ but, as can be seen in Fig. 3, these materials suffer different catalyst deactivation profiles with time-onstream (TOS). The conventional SSZ-13 material shows the fastest catalyst deactivation with methanol conversion dropping below $50 \%$ after 310 min of TOS. In contrast, both SSZ-39 materials show higher catalyst lifetime than the conventional SSZ-13 catalyst, with methanol conversion dropping below $50 \%$ after 540 and 940 minutes of TOS for SSZ-39_1 and SSZ-39_2, respectively (see Fig. 3).

These different deactivation profiles reveal that the physicochemical properties of each catalyst clearly influence their catalytic behaviour. Indeed, it has been broadly described in the literature that small pore zeolite-based MTO catalysts with excessive Brönsted acidity or mass transfer restrictions within the crystals suffer from severe catalytic deactivation by coke formation. ${ }^{3}$ Thus, since the Brönsted acidity measured for the SSZ-13 material is lower than the Brönsted acidity observed for the SSZ-39 materials [see ammonia desorption values in Table S2 (ESI $\dagger$ )], the faster SSZ-13 catalyst deactivation must be mainly attributed to its larger crystal sizes compared to SSZ-39 materials [see Table S1 (ESI $\dagger$ )]. In a similar way, the small crystal sizes of the nanosized SSZ-39_2 material would mainly explain its remarkable catalyst lifetime increase compared to SSZ-39_1, since the Brönsted acidities of these two materials are similar [see Tables S1 and S2 (ESI +$)$ ]. The selectivities to the different reaction products have been compared at constant conversion of methanol [see Fig. S5 (ESI $\dagger$ )]. The results can allow detecting particular diffusion restrictions during the catalyst deactivation. However, these three materials show a linear dependence between the different product yields and methanol conversion [see Fig. S5 $(\mathrm{ESI}+)]$, indicating that the yields to the different products are not controlled by diffusion during deactivation. In other words, the deactivation of these SSZ-13 and SSZ-39 materials is "nonselective", and the selectivity to the different products is independent of the coke content or the level of catalyst deactivation. Similar "non-selective" deactivation profiles have been previously reported for ZSM- $5,{ }^{22}$ SSZ-13, ${ }^{23}$ SAPO- $34,{ }^{10 c, 13 a}$ and SAPO- $18 .{ }^{24}$ Moreover, 
comparing selectivities at constant conversion allows the discrimination of the influence of thermodynamical equilibrium of olefins, at $100 \%$ conversion of methanol + DME, from the true selectivity of the hydrocarbon pool at lower conversions. ${ }^{10 c}$

Regarding the product selectivities at different methanol conversion values, it can be clearly seen that the SSZ-13 and SSZ-39 materials show different product distributions [see Fig. S6 (ESI $\dagger$ )]. In general, it can be observed that the two SSZ-39 samples provide much higher selectivity to propylene and lower to ethylene than the conventional SSZ-13 material [see Fig. S6 (ESI $\dagger$ )]. Indeed, the C2/C3 ratio with TOS is much higher for the SSZ-13 material than that for the two SSZ-39 materials [see Fig. S7 (ESI +$)$ ]. Similar trends for the C2/C3 ratios have also been observed for the AEI and CHA structures in their SAPO forms. ${ }^{25,26}$ This different product selectivity could be attributed to the different shape of the zeolitic cages present in both materials, being the AEI cage basket-shaped and wider at the bottom than the CHA cage, which is more symmetric. ${ }^{15,25}$ Thus, the larger size of the AEI cage could allow the formation of aromatics within the "hydrocarbon pool" transient-state with the adequate size to increase the propylene selectivity. ${ }^{11 a}$ In fact, other small pore zeolites, such as RUB-13 (RTH), presenting larger cages than those of AEI and CHA, have also shown higher selectivity to propylene. ${ }^{27}$

The values of hydrogen transfer index $(\mathrm{HTI}, \mathrm{C} 3 / \mathrm{C} 3=)$ for the different materials are summarized in Fig. S8 (ESI $\dagger$ ). The comparison of the HTI values at constant methanol conversion reveals the presence of two well differentiated zones [Fig. S8 (ESI $\dagger$ )]. The "initial" hydrogen transfer values at $100 \%$ methanol conversion, are higher due to the formation of the hydrocarbon pool aromatic species. In fact, the formation of hexamethylbenzene cations implies cyclization and hydrogen transfer to an olefin precursor that desorbs as paraffin (propane). Once the hydrocarbon pool is formed within all the cages, subsequent cyclization on the previously formed monoaromatic species causes their growth and progressive deactivation. These "secondary" hydrogen transfer reactions are lower and appear in a second zone, in which methanol conversion is below $100 \%$. In this sense, the higher "initial" HTI values observed for the SSZ-39 samples could be explained by their higher acidity [see Table S2 (ESI $\dagger$ )], while the higher "secondary" HTI values observed for the SSZ-13, which is in agreement with the faster catalytic deactivation observed in the methanol reaction, could be mainly attributed to its larger crystal sizes (see Fig. 2). Regarding SSZ-39 materials, the nanosized SSZ-39_2 shows the lowest HTI values [see Fig. S8 (ESI $\dagger)$ ], as could be expected by its smaller crystal sizes.

In summary, the synthesis of the nanosized SSZ-39 material has been achieved following a zeolite-to-zeolite transformation methodology, using a high silica FAU zeolite as a Si and Al source and tetraethylphosphonium (TEP) cations as OSDAs. The catalyst lifetime of the nanosized SSZ-39 material for the MTO reaction is remarkably high compared to the catalyst lifetime observed for conventional SSZ-13 and SSZ-39 materials.

Financial support by the Spanish Government-MINECO through "Severo Ochoa" (SEV2012-0267), MAT2015-71261-R, and CTQ2015-68951-C3-1-R is acknowledged. The European Union is also acknowledged by the SYNCATMATCH project (Grant Agreement no. 671093). N. M. thanks MINECO for economical support through pre-doctoral fellowship (BES-2013-064347). J. Y. and A. C. thank the National Natural Science Foundation of China (21320102001) for supporting this work.

\section{References}

1 (a) J. Biswas and I. E. Maxwell, Appl. Catal., 1990, 63, 197; (b) P. O'Connor, Stud. Surf. Sci. Catal., 2007, 166, 227.

2 A. Corma; J. Mengual and P. J. Miguel, Appl. Catal., A, 2012, 220, 417.

3 (a) P. Barger, Zeolites for Cleaner Technologies, Catalytic Science Series, 2002, vol. 3, p. 239; (b) P. Tian, Y. Wei, M. Ye and Z. Liu, ACS Catal., 2015, 5, 1922; (c) M. Moliner, C. Martínez and A. Corma, Chem. Mater., 2014, 26, 246.

4 M. Stöcker, Microporous Mesoporous Mater., 1999, 29, 3.

5 S. Wilson and P. Barger, Microporous Mesoporous Mater., 1999, 29, 117.

6 (a) B. P. C. Hereijgers, F. Bleken, M. H. Nilsen, S. Svelle, K. P. Lillerud, M. Bjørgen, B. M. Weckhuysen and U. Olsbye, J. Catal., 2009, 264, 77; (b) W. Song, J. F. Haw, J. B. Nicholas and C. S. Heneghan, J. Am. Chem. Soc., 2000, 122, 10726.

7 D. Chen, K. Moljord and A. Holmen, Microporous Mesoporous Mater., 2012, 164, 239.

8 S. C. Larsen, J. Phys. Chem. C, 2007, 111, 18464.

9 (a) F. Schmidt, S. Paasch, E. Brunner and S. Kaskel, Microporous Mesoporous Mater., 2012, 164, 214; (b) Q. Sun, N. Wang, G. Guo, X. Chen and J. Yu, J. Mater. Chem. A, 2015, 3, 19783; (c) Q. Sun, N. Wang, D. Xi, M. Yang and J. Yu, Chem. Commun., 2014, 50, 6502; (d) H. Yang, Z. Liu, H. Gao and Z. Xie, J. Mater. Chem., 2010, 20, 3227.

10 (a) Q. Sun, N. Wang, G. Guo and J. Yu, Chem. Commun., 2015, 51, 16397; (b) G. Yang, Y. Wei, S. Xu, J. Chen, J. Li, Z. Liu, J. Yu and R. Xu, J. Phys. Chem. C, 2013, 117, 8214; (c) Z. Li, J. Martinez-Triguero, P. Concepcion, J. Yu and A. Corma, Phys. Chem. Chem. Phys., 2013, 15, 14670.

11 (a) Y. Bhawe, M. Moliner-Marin, J. D. Lunn, Y. Liu, A. Malek and M. Davis, ACS Catal., 2012, 2, 2490; (b) F. Bleken, M. Bjørgen, L. Palumbo, S. Bordiga, S. Svelle, K. P. Lillerud and U. Olsbye, Top. Catal., 2009, 52, 218; (c) L. T. Yuen, S. I. Zones, T. V. Harris, E. J. Gallegos and A. Auroux, Microporous Mater., 1994, 2, 105.

12 (a) L. Wu, V. Degirmenci, P. C. M. M. Magusin, N. J. H. G. M. Lousberg and E. J. M. Hensen, J. Catal., 2013, 298, 27; (b) Y. Ji, M. A. Deimund, Y. Bhawe and M. E. Davis, ACS Catal., 2015, 5, 4456.

13 (a) Z. Li, J. Martínez-Triguero, J. Yu and A. Corma, J. Catal., 2015, 329, 379; (b) J. Wang, D. Fan, T. Yu, J. Wang, T. Hao, X. Hu, M. Shen and W. Li, J. Catal., 2015, 322, 84.

14 (a) S. I. Zones, Y. Nakagawa, S. T. Evans and G. S. Lee, US5958370A, 1999; (b) P. Wagner, Y. Nakagawa, G. S. Lee, M. E. Davis, S. Elomari, R. C. Medrud and S. I. Zones, J. Am. Chem. Soc., 2000, 122, 263.

15 M. Dusselier, M. A. Deimund, J. E. Schmidt and M. E. Davis, ACS Catal., 2015, 5, 6078.

16 (a) M. Moliner, C. Franch, E. Palomares, M. Grill and A. Corma, Chem. Commun., 2012, 48, 8264; (b) M. Dusselier, J. E. Schmidt, R. Moulton, B. Haymore, M. Hellums and M. E. Davis, Chem. Mater., 2015, 27, 2695.

17 (a) T. Maruo, N. Yamanaka, N. Tsunoji, M. Sadakane and T. Sano, Chem. Lett., 2014, 43, 302; (b) T. Sonoda, T. Maruo, Y. Yamasaki, N. Tsunoji, Y. Takamitsu, M. Sadakane and T. Sano, J. Mater. Chem. A, 2015, 3, 857.

18 N. Martin, C. R. Boruntea, M. Moliner and A. Corma, Chem. Commun., 2015, 51, 11030.

19 (a) L. Tosheva and V. P. Valtchev, Chem. Mater., 2005, 17, 2494; (b) M. Moliner, F. Rey and A. Corma, Angew. Chem., Int. Ed., 2013, 52, 13880.

20 Z. Yan, D. Ma, J. Zhuang, X. Liu, X. Liu, X. Han, X. Bao, F. Chang, L. Xu and Z. Liu, J. Mol. Catal. A: Chem., 2003, 194, 153.

21 S. I. Zones, US4544538, 1985.

22 F. L. Bleken, T. V. W. Janssens, S. Svelle and U. Olsbye, Microporous Mesoporous Mater., 2012, 164, 190.

23 W. Skistad, S. Teketel, F. L. Bleken, P. Beato, S. Bordiga, M. H. Nilsen, U. Olsbye, S. Svelle and K. P. Lillerud, Top. Catal., 2014, 57, 143.

24 T. Álvaro-Muñoz, C. Márquez-Álvarez and E. Sastre, Top. Catal., 2016, 59, 278 .

25 R. L. Smith, S. Svelle, P. del Campo, T. Fuglerud, B. Arstad, A. Lind, S. Chavan, M. P. Attfield, D. Akporiaye and M. W. Anderson, Appl. Catal., A, 2015, 505, 1.

26 J. Chen, J. Li, Y. Wei, C. Yuan, B. Li, S. Xu, Y. Zhou, J. Wang, M. Zhang and Z. Liu, Catal. Commun., 2014, 46, 36.

27 T. Yokoi, M. Yoshioka, H. Imai and T. Tatsumi, Angew. Chem., Int. $E d ., 2009,48,9884$. 